\title{
Pelatihan Endorphin Massage bagi Mitra Dukun Pijat Tradisional guna Menurunkan Angka Morbiditas Ibu Hamil di Desa Banjar-Tanah Merah Bangkalan
}

\author{
Miftahul Khairoh ${ }^{1 *}$, Shinta Nur Rochmayanti. ${ }^{2}$ \\ ${ }^{1,2}$ Universitas dr. Soetomo, Fakultas Ilmu Kesehatan, Prodi D3 Kebidanan \\ *miftahkhairoh34@gmail.com
}

Received 14 January 2019; Accepted 2 March 2019; Published 10 March 2019

\begin{abstract}
ABSTRAK
Kegiatan pengabdian pada masyarakat berupa pendampingan dukun pijat tradisional yang umumnya dijadikan mitra pijat oleh Ibu hamil dengan memberikan pengetahuan dan keterampilan dalam melakukan pijat secara benar dan aman. Para dukun diberikan pengetahuan tentang fisiologis perubahan fisik ibu hamil serta keluhan fisik penyerta seiring pertambahan usia kehamilan. Kemudian dilanjutkan dengan memberikan pelatihan keterampilan endorphin massase kepada mitra dukun secara berkala sampai bisa dan mampu melakukan secara mandiri. Pengabdian ini dilakukan di desa Banjar Kecamatan tanah Merah. Sasaran dalam pengabdian masyarakat ini adalah seluruh ibu hamil baik TM I, II dan III yang ada di desa Banjar, Kecamatan Tanah Merah Kabupaten Bangkalan Madura. Sasaran adalah kelompok wanita dengan resiko kesakitan dan kematian yang tinggi, oleh karena proses kehamilan merupakan kejadian alamiah namun memiliki resiko. Pengabdian ini dilakukan melalui beberapa tahapan, yaitu diawali dengan penyampaian materi dan demonstrasi teknik memijat endorphin massage pada ibu hamil. Kemudian, mitra dukun akan diajari langsung bagaimana teknik yang benar dan aman dalam melakukan endorphin massage pada ibu hamil. Setelahan dijarkan langsung, maka mitra dukun akan di evaluasi bagaimana teknik saat melakukan endorphin massage. Mitra dukun akan terus dibimbing sampai mahir melakukan pijat endorphin massage pada ibu hamil.
\end{abstract}

Kata kunci: Endorphin massase, dukun, pijat tradisional

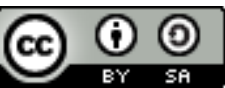

This is an open-acces article distributed under the terms of the Creative Commons Attribution-ShareAlike 4.0 International License.

\section{PENDAHULUAN}

Dewasa ini, kebutuhan akan pijat bukan hanya dibutuhkan karena pijat capek atau lelah, namun menjadi salah satu kebutuhan oleh ibu yang sedang hamil. Oleh karena masa kehamilan merupakan masa dimana rasa tidak nyaman secara fisik menjadi keluhan yang hampir semua ibu hamil merasakannya. Keluhan yang sering terjadi pada ibu hamil, khususnya trimester III adalah nyeri punggung. Nyeri punggung merupakan nyeri yang terjadi pada area lumbosakral. Nyeri punggung biasanya akan meningkat intensitasnya seiring dengan pertambahan usia kehamilan karena nyeri ini merupakan akibat pergeseran pusat gravitasi dan perubahan postur tubuhnya.

Perubahan ini disebabkan oleh berat uterus yang membesar, membungkuk yang berlebihan, berjalan tanpa istirahat, dan angkat beban. Gejala nyeri punggung ini juga disebabkan oleh hormon estrogen dan progesteron yang mengendurkan sendi, ikatan tulang dan otot dipinggul. Selain zat yang 
mampu merangsang kepekaan nyeri, tubuh juga memiliki zat yang mampu menghambat (inhibitor) nyeri yaitu endorfin dan enkefalin yang mampu meredakan nyeri. Beberapa hormone kehamilan menyebabkan ligamen yang berada di atara di tulang pelvis (panggul) melunak dan sendi melonggar sebagai persiapan untuk melahirkan.

Salah satu cara mengatasi nyeri punggung adalah dengan teknik pijat lembut yang disebut Endorphin massage, untuk melepaskan senyawa endorpin yang merupakan pereda rasa sakit alami didalam tubuh. Hormon endorphin adalah morfin alami tubuh yang bisa menekan rasa sakit dan meningkatkan kekebalan tubuh agar bekerja optimal. Untuk meningkatkan sekresi hormon endorfin dapat dilakukan dengan melakukan pijat endorphin.

Pijat Endorphin atau terapi sentuhan ringan merupakan sebuah terapi sentuhan/pijatan ringan yang cukup penting diberikan pada wanita hamil, diwaktu menjelang hingga saatnya melahirkan. Hal ini disebabkan karena pijatan merangsang tubuh untuk melepaskan senyawa Endorphin yang merupakan pereda rasa sakit dan dapat menciptakan perasaan nyaman.

Sepuluh tahun lalu American Pregnancy Association (APA) membuat sebuah studi tentang hubungan pijat prenatal dengan hormon-hormon penenang dan penyebab stres. Hasilnya, pijat prenatal terbukti dapat memperbaiki mood dan meningkatkan kesehatan kardiovaskuler. Menurut penelitian ini, ibu hamil yang dipijat tiap 2 minggu sekali, selama 5 minggu, maka kadar hormonhormon penyebab stresnya (norepinephrine dan kortisol) akan menurun. Sebaliknya, kadar hormon dopamine dan serotonin pada bumil akan meningkat. Kekurangan dua hormon itu dapat meningkatkan risiko depresi kehamilan. Perubahan kadar hormon tersebut menurunkan risiko komplikasi pada newborn, seperti berat badan lahir rendah.

Pemanfaatan mitra dukun pijat tradisional ini dilakukan dengan pertimbangan bahwa dukun pijat merupakan mitra ibu hamil untuk melepaskan lelah dan rasa tidak nyaman pada kehamilan. Sehingga dirasa penting untuk dilakukan pelatihan kepada mitra dukun untuk dilatih teknik pijat ibu hamil secara benar dan nyaman. Hal ini ditujukan agar morbiditas atau angka kesakitan pada ibu hamil dapat diturunkan, dan meningkatkan angka kesehatan dan kesejahteraan ibu hamil. Selain itu, pelatihan pijat endorphine massage pada mitra dukun ini juga diharapkan mampu meningkatkan nilai kesejahteraan para dukun pijat.

\section{BAHAN DAN METODE}

Kegiatan pengabdian pada masyarakat berupa pendampingan dukun pijat tradisional yang umumnya dijadikan mitra pijat oleh Ibu hamil dengan memberikan pengetahuan dan keterampilan dalam melakukan pijat secara benar dan aman. Para dukun diberikan pengetahuan tentang fisiologis perubahan fisik ibu hamil serta keluhan fisik penyerta seiring pertambahan usia kehamilan. Kemudian dilanjutkan dengan memberikan pelatihan keterampilan endorphin massase kepada mitra dukun secara berkala sampai bisa dan mampu melakukan secara mandiri. Pengabdian ini dilakukan di desa Banjar Kecamatan tanah Merah, karena di wilayah tersebut masih banyak praktik dukun pijat tradisional. Pengabdian ini bekerjasama juga dengan Puskesmas Banjar untuk mengajarkan para mitra dukun teknik pijat endorphin massage pada ibu hamil.

Pijat Endorphin atau terapi sentuhan ringan merupakan sebuah terapi sentuhan/pijatan ringan yang cukup penting diberikan pada wanita hamil, diwaktu menjelang hingga saatnya melahirkan. untuk melepaskan senyawa endorpin yang merupakan pereda rasa sakit alami didalam tubuh. Hormon endorphin adalah morfin alami tubuh yang bisa menekan rasa sakit dan meningkatkan kekebalan tubuh agar bekerja optimal. Untuk meningkatkan sekresi hormon endorfin dapat dilakukan dengan melakukan pijat endorphin. Bahan yang dibutuhkan yaitu Baby oi, Jarik, Matras, Alas/perlak.

\section{HASIL}

Tersusun kesepakatan antara tim pengabdian masyarakat FIKES UNITOMO dengan pihak Puskesmas Banjar. Tersusun buku ajar tentang Endorphin massase pada Ibu hamil. Terbentuknya kesepakatan antara tim pengabdian masyarakat FIKES UNITOMO, mitra dukun dan ibu hamil untuk dilakukan pelatihan Endorphin massase. 100\% Dukun di Desa Banjar menghadiri penyuluhan dan pelatihan Endorphin massase.

\section{Journal of Community Engagement in Health}


12 orang ibu hamil menghadiri dan menjadi peserta Endorphin massase oleh tim pengabdian masyarakat FIKES UNITOMO dan mitra dukun. 1 orang tim dari Puskesmas Banjar turut menghadiri kegiatan penyuluhan dan pelatihan Endorphin massase dan diharapkan dapat menjadi bibit bagi transfer knowledge kepada masyarakat sekitar. 80\% ibu hamil memahami akan pentingnya teknik pijat kehamilan yang benar dan aman. 100\% mitra dukun mengerti tentang teknik Endorphin massase. Mitra dukun mengerti dan memahami tentang peluang usaha terhadap pelayanan jasa Endorphin massase kepada ibu hamil.

\section{PEMBAHASAN}

Kegiatan berjalan dengan sangat baik. Seluruh peserta antusias dan pro aktif terhadap kegiatan yang berlangsung. Seluruh mitra dukun mendapat 2-4 kali kesempatan untuk berlatih melakukan Endorphin massase kepada ibu hamil. Pada kegiatan ini 86\% undangan penyuluhan manfaat Endorphin massase dari desa Banjar kecamatan Galis Bangkalan, menghadiri acara penyuluhan di kediaman bapak kepala desa/klebun.

Jumlah sasaran pada pelatihan ini yaitu 22 orang dan jumlah peserta 21 orang (95\%).Ibu hamil juga merasa sangat terbantu karena dapat mengurangi nyeri punggung (back pain) yang selama ini dirasakan. Seluruh ibu hamil memahami bahwa Endorphin massase adalah salah satu terapi non farmakologi untuk mengurangi atau meringankan rasa sakit, dan sentuhan ringan untuk membantu memberikan rasa tenang dan nyaman.

Peserta sangat antusias terhadap materi penyuluhan tentang manfaat Endorphin massase yang diberikan oleh tim pengabdian masyarakat FIKES UNITOMO. Serta adanya pemutaran video Endorphin massase dan materi bergambar yang bisa dipelajari dan di baca ulang di rumah. Mitra Dukun juga merasa sangat diuntungkan karena bisa mendapatkan pemasukan tambahan, dengan tariff massase per ibu hamil sekitar 40-60 ribu. Pihak Puskesmas Banjar merasa sangat terbantu dengan bertambahnya keterampilan para Dukun khususnya Endorphin massase sehingga besar harapan dapat menurunkan angka kesakitan dan kematian ibu hamil. Pihak Puskesmas berharap akan ada kegiatan serupa di kesempatan berikutnya.

\section{KESIMPULAN}

Pemanfaatan mitra dukun pijat tradisional ini dilakukan dengan pertimbangan bahwa dukun pijat merupakan mitra ibu hamil untuk melepaskan lelah dan rasa tidak nyaman pada kehamilan. Sehingga dirasa penting untuk dilakukan pelatihan kepada mitra dukun untuk dilatih teknik pijat ibu hamil secara benar dan nyaman. Hal ini ditujukan agar morbiditas atau angka kesakitan pada ibu hamil dapat diturunkan, dan meningkatkan angka kesehatan dan kesejahteraan ibu hamil. Selain itu, pelatihan pijat endorphine massage pada mitra dukun ini juga diharapkan mampu meningkatkan nilai kesejahteraan para dukun pijat.

\section{UCAPAN TERIMA KASIH}

Ucapan terimakasih penulis sampaikan untuk pihak-pihak yang telah membantu dalam mensukseskan kegiatan, khususnya untuk Universitas dr. Soetomo Surabaya yang telah mendanai kegiatan pengabdian masyarakat Program Kemitraan Masyarakat (PKM) ini.

\section{REFERENSI}

Astuti, \& Hutari, P. (2012). Buku Ajar Asuhan Kebidanan Ibu Kehamilan. Yogyakarta: Rohima Press.

Association of Chartered Physiotherapist in Woman Health. (2011). Pregnancy Related Pelvic Girdle Pain Formerly Known as Symphysis Pubis Disfunction ACPWH.

\section{Journal of Community Engagement in Health}


Aprilia \& Ratih. (2016). Penerapan Endorphine Massage Terhadap Penurunan Nyeri Punggung Pada Ibu Hamil Trimester III Di BPM Ismoyowati Mirit. (Jurnal Kesehatan): Sekolah Tinggi Ilmu Kesehatan (diakses 02 Januari 2018).

Bull, Eleanor, \& Archard, G. (2013). Simple Guide: Nyeri Punggung.

Cunningham, \& Gary. (2008). Obstetri Williams Volume I. Jakarta: EGC.

Departemen Kesehatan Republik Indonesia (Depkes RI). (2011). Pelayanan Asuhan Kehamilan. http://www.dinkes.go.id. Diakses 20 Februari 2018.

Fauci, A., S., Kasper, D., L., Longo, D., L., et al. (2008). Back and Neck Pain. Dalam Harrison's Principles of Internal Medicine. 17th Edition. New York: McGrawHill.

Hanafiah, T., \& Mohammad. (2008). Diagnosis Kehamilan Dalam Buku Ilmu Kebidanan. PT Bina Pustaka Sarwono Prawirohardjo. Jakarta.

Kuswandi. (2011). Pengaruh Endorphin Massage Terhadap Intensitas Nyeri Kala I Persalinanan Normal Ibu Primipara di BPS S dan B Demak Tahun 2011. http: jurnal.Unimus.ac.id. Diakses 25 April 2018.

Leung, \& Lawrence. (2012). From Ladder to Platform: A New Concept For Pain Management. Kanada: Journal Of Primary Health Care.

Saifuddin, \& Bahri, A. (2012). Buku Acuan Nasional Pelayanan Kesehatan Maternal dan Neonatal. Jakarta: Bina Pustaka Sarwono Prawirohardjo.

Setiawati. (2012). Menghilangkan Nyeri Saat Persalinan dengan Endorphin Massage. http://www. dwp. purworejo. org / berita -129-menghilangkan nyeri- saat-persalinan-dengan-endorphin-massage. Diakses tanggal 25 Februari 2018.

Sinclair, \& Constance. (2010). Buku Saku Kebidanan. Jakarta: EGC.

Suzanne, S., Brenda, B., Brunner \& Suddarth. (2002). Buku Ajar Keperawatan Medikal Bedah. Jakarta: EGC.

\section{Journal of Community Engagement in Health}

